\title{
Challenges Young Female Entrepreneurs Face: An Ethnographic Study of Women Entrepreneurs Who Buy Things in Thailand to Sell in Congo
}

\author{
Tshipama Laeticia \\ Graduate School, Stamford International University, Bangkok, Thailand \\ Email: laeticianawej@yahoo.fr
}

Received 17 November 2015; accepted 27 January 2016; published 30 January 2016

Copyright (C) 2016 by author and Scientific Research Publishing Inc.

This work is licensed under the Creative Commons Attribution International License (CC BY). http://creativecommons.org/licenses/by/4.0/

(c) (i) Open Access

\begin{abstract}
The purpose of this study was to analyze challenges young female entrepreneurs face and the resources they need with a view to recommend strategies to empower young female entrepreneurs. The theoretical base of the study was organizational ecology theory. Focused group discussions, survey, and examination of primary documents were used to collect data. The findings of the study show that government laws and regulations, cultural beliefs, lack of capital, lack of business partners, lack of information, difficulties to obtain capital based on gender, discrimination against women in business, and availability of more women in business than women highly affected women entrepreneurs in Congo. The study also shows that the family unit plays a more central role in providing business opportunities for young female entrepreneurs in Congo, especially in the absence of government intervention and private sector incentives.
\end{abstract}

\section{Keywords}

Female Entrepreneurs, Ethnography, Case Study, Congo

\section{Introduction}

An entrepreneur is a person who undertakes and operates a new enterprise and assumes accountability for some inherent risks [1]. Entrepreneurship is a process of creating new wealth. This process focuses on discovery, creation, and profit exploitation of markets for goods and services. Therefore, entrepreneurship entails activities of an individual or a group aimed at initiating an economic enterprise, under legal form of business [2]. 
Entrepreneurs are often at the mercy of the larger macro-economic conditions. The 2008/2009 financial crisis for instance negatively affected markets that relied largely on global trade. As a result, millions of people lost jobs and businesses closed down [3]. Such conditions are likely to severely affect new business than established businesses because established business have more access to information, enjoy established reputation, and have access to finance than newly established businesses [2].

In Congo, the advance of self-employment is increasingly becoming an alternative to seeking employment in the public or private sector, which often has limited opportunities. This has often led to small business under difficult economic conditions [3]. Therefore, as an expanding economic dimension, entrepreneurship raises an interest for study.

Entrepreneurship in Congo has a gender dimension as well. Some sectors for instance health are dominated by men, majority of who are medical professionals, who use their savings, contributions and support from friends and relatives to start enterprises in the health sector. These entrepreneurs often run enterprises in areas where public services and larger private sector organizations presence is scarce [4]. This study indicates that gender and background contribute to one's capability to start and run an enterprise [5].

Entrepreneurship has prevailed even areas affected by conflict. Local entrepreneurs have been able to create Innovative networks that ensure effective supply chain and partnerships that support businesses and access to finance. Local entrepreneurs have over time built rich and strong networks of social relations within and outside the country, based on which they coordinate business and built social capital for business sustainability [6]. While general perspectives on entrepreneurship in Congo dominate literature, perspectives on young women entrepreneurs, the business they run, and the challenges they face remain scarce.

The primary role of entrepreneurship is to discover new business opportunities, identify and mobilize available resources, create and run new business enterprises that provide the missing goods and services. Congo has increasing business opportunities coming as a result of the limitations of government and the private sector to adequate employment for its citizens. In the midst of this challenge, female entrepreneurs emerge to seize the opportunity, create and run businesses, and compete with other business ranging from larger firms to smaller businesses. While this is an interest issue to study, studies on female entrepreneurship in Congo have focused on entrepreneurs located inside the country. As a result, little is known of young female entrepreneurs buying things in Thailand and selling them in Congo. This group of entrepreneurs is faced with a different business environment running their business in two different country contexts. Therefore, this study seeks to analyze contextual challenges young female entrepreneurs face and the resources they need, with a view to recommend strategies to empower young female entrepreneurs. The study focused on two questions: What contextual challenges do young female entrepreneurs face? What resources do young female entrepreneurs need in order to address external threats?

\section{Theoretical Framework}

Organizational ecology theory assumes that organizations are interwoven with the environment. Therefore, organizations like living things are affected by external environmental forces such as social, economic, and political conditions. These conditions can make an organization grow or survive. If the organization does not fit in this environment, it will die. As a result, organizations need to respond to the external environmental forces for them to develop or survive. The survival of the organization depends on its capacity to withstand the pressure from external forces. Therefore, what can make an organization survive such environmental pressures are things such as 1) the strategies an organization adopts; 2) the ability of the top manager to understand and analyze the environment, and to take appropriate actions; and other internal factors such as resources, structure, and size of the organization [7].

\subsection{Political Factors}

Studies show that what goes on in the global economy affects retail business. This means that retail businesses are exposed to challenges in the global economy just as large business firms do. This is because retail business operates under business-business relationship. In this case, issues affecting larger business trickle down to retail business. On the other hand, issues affecting small businesses trickle up affecting larger businesses too [8]. In countries with multi-party democracy, large business firms usually fund political parties with hope that when such political parties come to power, they will influence business policies. Most of this money goes into political 
campaigns. Data from Australia indicates that about 450 large business companies have funded political parties in the recent years. When this happen, small business which often have little or no money to fund political parties end up with no influence on government. As a result, government policies and agenda tend to favor large business than small businesses. In such cases, small businesses may be dislocated and run out of business, because of the political influence large companies have on government [9].

\subsection{Institutional Factors}

Government laws, regulations, procedures have an effect on businesses because they can influence or determine whether a business will grow, expand or shrink. This is due to the pressure these policies put on business for example high taxes, strict controls, or loosening controls on some products hence flooding the market. When government policies for example promote international trade, they may allow multinational Corporations to dominate; this may kill small businesses. If government wants to promote small business, it can for example change baking rules to make it easy to open accounts, save with little or no interests, and borrow loans at a lower interest rate. Government agencies for instance commercial courts can help to promote businesses by enforcing business contracts and ruling cases promptly and with fairness [10].

\subsection{Socio-Cultural Factors}

Socio-cultural factors for instance ethical decision making is influenced by cultural value system. When Chinese and American students were presented with hypothetical scenarios and asked to make ethical decisions; they demonstrated two different ethical sets of ethical decision making behaviors which were identical to the Chinese versus American cultures [11]. The study for instance shows those Chinese students made less ethical decisions in areas such as compliance with the law; proper use of company records; and trading on inside information. These behaviors reflected the wider Chinese socio-cultural context compared to the American socio-cultural context. The study implies that the behavior of individuals would most likely reflect the wider socio-cultural value system than underlie the context these individuals come from. Culture also influences the demand and supply of products. This means that it can directly affect the sales of a product hence can determine whether a business can grow or fail. Japanese consumer culture shows that customers take into account cultural considerations such as the country of origin of a particular product when determining whether or not to buy a product [12]. This study shows that culture influences the import flow of goods in the country.

\subsection{Technical Factors}

One of the important features of technical factors in business is the use of technology to promote business.

Information technology provides support, instructional and learning base for businesses that seek new ways to grow or improve their products and services. One of the key areas is making it possible to do online research. This reduces costs, logistics, and constrains incurred in off line business research and development [13]. The way information technology is used affect the extent it will be useful in increasing economic returns. If it is used well, it will yield more than if it was not well utilized for instance when it is used in e-commerce compared to when it is just used for communication. Wealthy countries will largely have good internet utilization than nations that are still developing because of infrastructure deficiencies as well as lack of adequate skills to maximize the online platform for business [14].

\subsection{Economic Factors}

When a country experiences an economic downturn, employment opportunities tend to shrink. In this case, there is most people begin to venture into entrepreneurship. On the other hand, hash prevailing economic conditions affect businesses forcing them to adjust on their costs of doing business in order to survive difficult economic conditions [15]. Another way to look at economic conditions in a country is to look at what government is doing to make the investment environment better; as well as business environment conducive for running business. A study on South Korea indicates that government provided support to boost innovations in business. This has the recent years increased the financial base for businesses to do business and stimulate the market. To a large extent, government focused on promoting enterprise development including apart from financing, adopting imported technologies [16]. 


\subsection{The Manager's Leadership/Management Capabilities}

Successful entrepreneurship is partly based on the ability of the manager to identify and utilize social and human capital. Social capital refers to the influential or a resourceful individual the entrepreneur knows while human capital refers to the entrepreneur knows which they can use to effect change in their organizations. The knowledge of the entrepreneur influences the entrepreneurs self-confidence and motivation to venture into and explore new business ventures, to compete and experiment in business. Through education the entrepreneur builds resources like hope, confidence, resilience, and optimism [17]. These also relates to the entrepreneurs ability to seek and access information, adopt better management practices.

\section{Methodology}

This study is an ethnographic case study. Ethnography is a study about a particular group of people. In this case the study is about female entrepreneurs from Congo that buy products in Thailand to sell in Congo. As a study of context specific young female entrepreneurs, the study adopts a gender perspective through which the business world is assumed to be male oriented. In this business world, socio-cultural norms and beliefs, government regulations, and the larger business environment tends to disadvantage women. As a kind of "sociology of women" in business; the study seeks to understand how these socio-cultural, economic, and political forces constitute business threats to young female entrepreneurs [18]. The study for example examines the business experiences of these young female entrepreneurs as they face these forces. It covers ways in which these entrepreneurs draw resources from their own social setting and networks, and the business relationships they anchor their business on, as they strive to combat external socio-cultural, economic and political forces threatening their businesses.

The following features of the ethnography were used to guide used in the study:

1) Focus on how a particular group and how it works. In this case, the study focused on the external threats young female entrepreneurs face and how these entrepreneurs address these threats. Unique to this was their entrepreneurship interaction across Thailand and Congo business environments as well as in the male dominant business world, where business norms and practices tend to favor men.

2) Culture sharing group. The young female entrepreneurs studied here were: young African Congolese women who lived in Congo but from time to time travelled to Thailand, where they stayed for a while purchasing business products before they returned to sell them from in Congo; majority of them came from business families and had their first experience in business over time as they grew up; well exposed to online business practices and social networking; and had considerable business and social capital support from their families.

3) Themes and theory selection. The theoretical underpinning of this study was organizational ecology theory. The theory assumes that contextual factors such as social, economic, and political conditions of a place affect the survival or life of an organization. This can make an organization survive or grow if the organization fits that environment. Therefore, the role of the organization is to respond to the external environmental forces that affect it. This largely depends on the ability of the leaders and the capacity of the organization to stand environmental threats.

Themes studied were derived from literature review. The themes were categorized into the following two major categories. a) Personal characteristics of the respondents/participants: age of the respondents; years of experience; level of education; business ventures; source(s) of capital/finance; professional training in business; frequency of travel to Thailand for business; reasons for choosing international trade/entrepreneurship. b) business conditions: lack of capital; lack of information; lack of skills; lack of business partners; cultural beliefs hinder business; government laws/regulations hinder business; politics hinder business; it is harder to obtain capital based on gender; women face discrimination in business; men are respected more in business than women.

4) Cultural concepts. As highlighted in the previous section; the focus was on the dominant hegemony or socio-cultural, political, or economic power structures; or forces that constitute external threats to business. The work of the researcher was to identify, analyze and expose them.

5) Data collection from the setting. The researcher collected data from participants both in Thailand and Congo. The researcher interacted with both Thailand and Congo business environment; and went through some of the basic processes participants went through for instance travel processes, regulations, and the physical contextual challenges. The researcher came from the same socio-cultural background with the participants in the study. Therefore, this enabled the researcher to understand the meaning of different concepts and experiences of 
the participants.

6) Sources and methods of Data. Data was collected through multiples techniques for example focused group discussions, observation of primary documents; survey; and personal interaction with the world in which the participants conducted their business. Survey in ethnography is meant to elicit information that depicts a broader picture of the participants' world and experiences. This involves the social, economic, political and cultural issues from the context [19]. The survey questionnaire contained both closed and open-ended questions. It focused on the items highlighted in the previous section on theory and themes. Primary documents provided a commercial and professional background on the entrepreneurial endeavors of the participants. Three Focus Groups of three members in each group were recruited for Focused Group Discussion. The goal was to capture the reaction or feelings of the participants as decision makers in their businesses. They were also used to help interpret the results of a survey [20].

7) Description. The analysis and description studied each of the themes highlighted in this study as a distinctive item of research and how it fit into the larger scope of the study. While describing the business conditions and personal characteristics of the participants; the researcher focused on exposing the external threats that young female entrepreneurs were not resourced enough to tackle. The goal was to sensitize and mobilize the reader along issues affecting young female entrepreneurs, especially this kind of group.

From time to time, participants in the study traveled to Thailand where they stayed for some time purchasing products then travelled along with them to Congo. As entrepreneurs, they interacted with the Congo and Thai business environments when they made business decisions and strategies to run their business entities. Therefore, they possessed both professional knowledge and experience regarding the context in which they worked, and the contextual challenges they experienced. As participants in the study, they had the capacity to provide analytical view on the multiple causal linkages between the business entities they ran and the environmental issues that affected them.

The researcher new the participants' way back before the research began. The researcher was a business lady who had known the participants for a long time and interacted with them from time to time. She often interacted with them while doing business and also during other social occasions. As a result, she purposively selected the participants because had access to them, they had over time formed formidable social ties, and because they were available for her study. The aim of the previous interactions was to identify beforehand, and choose participants who the researcher anticipated that they had the information the researcher was looking for. This approach is good for studies that seek to explore specific knowledge; therefore the researcher goes to the particular participants who have specialized knowledge or information about the particular issue under study [21]. Entry into the business world of the participants was based on the researchers' social networks such as friendships and acquaintances. The researcher had prior informal social connections with some entrepreneurs which provided for a quicker entry into the site.

Access to participants was a continuous process. It was continuous because it involved a series of meetings or interactions between the researcher and the participants. The process also involved negotiating the terms of the study, time, and consent [18]. The process of collecting research began informally from initial simple conversations between the researcher and the participants. From these conversations, the researcher identified more accurately, participants who travelled to Thailand, to purchase products to sell in Congo. The initial understanding of the participants, their businesses, and the products they sold, and their willingness or potential to participate in the study came out of these informal interactions. While in Congo, researcher made personal visits to the participant's business premises, and held conservations about their businesses. While in Thailand, the researcher hanged out with participants or went to the market with them where she had some firsthand experience of their business. During this period, the researcher made arrangements with the participants concerning questionnaire filling schedules.

Note taking during personal interactions was done later to allow natural sharing information without interrupting the participants. However, focused group discussion data was collected while the discussion was in session since it would be difficult to remember all complex arguments about each item accurately if recorded later. The researcher used short-hard style which served as a guide to remember the details and linkages across issues. Block quotations were recorded in order to give voice to the discussion, as well as to capture the contextual perspective of the participants' experience.

Data was collected upon acceptance and consensus with the participants. Before collecting data, the researcher informed the participants about the research, and its significance, as well as their rights in case they chose to 
participate in the study. Once all the outstanding issues were resolved, data collection process began. The most challenging part of this study was that it was not easy to get the participants to fix data collection schedules. It took longer than the researcher anticipated before. Earlier, the researcher anticipated that she would collect data in 2 months. However, she was able to collect data in 5 months.

Descriptive statistics was used to analyze survey data. On the other hand qualitative data was analyzed based on the following steps. Qualitative data obtained from focused group discussion was analyzed by summarizing large data through note taking into themes, and eliciting themes that emerge from the data in light of the research questions. When analyzing data, significant statements, quotes, or sentences were highlighted. Transcribed data was read repeatedly in order to obtain meaning. Next, statements were clustered together according to themes. These statements and themes are then used to write and describe the participants' views. The final analysis is then written taking into account the bottom line in every thematic issue [22].

\section{Results of the Study}

\subsection{Years of Experience and Level Education}

The findings of this study show that $63 \%$ (19) of the respondents were between the ages of 30 - 35 years, while $37 \%$ (11) of the respondents were below 30 years. None of the respondents was below 25 years. This shows that even though small, the number of young female entrepreneurs indicates an emerging trend of young women in international entrepreneurship. The findings also indicated that 80\% (24) of the respondents had between 1 - 5 years of experience while $20 \%$ (6) of the respondents had below 1 year experience. This shows that majority of the respondents in the study had strong experience in international entrepreneurship. Regarding the level of education, $86 \%$ (26) of the respondents had high school education while 14\% (4) of the respondents had college/university education. None of the respondents had education below high school. This indicates that majority of the respondents had high school rather than college/university education.

\subsection{Types of Business Enterprises}

Most of them sold their products in stalls located in shopping malls, open markets, while a few sold their products from their homes, where they delivered the products to their customers who often ordered the products which were then delivered upon order. Typically, these enterprises were crafted along a sense of innovation meant to operate microenterprises whose activities focused on adapting situational mechanisms to tackle local barriers such as costs incurred when engaging in business-to-business relationship for example local whole sale-retailer relationship. To do so, entrepreneurs creatively maximized their access to opportunities by attempting to create an alternative to the traditional supply chain, in which case, instead of relying on local wholesalers for goods; they flew abroad to get them from the source, then sale them on retail market. The findings of the study also shows that 76\% (23) of the respondents were in fashion industry buying and selling products such as jewelry, clothes, shoes, and beauty products; while 24\% (7) of the respondents were in electronics, and household items. The common characteristics across the business ventures are that the entrepreneurs diversified their products rather than specialize in particular items only.

\subsection{Frequency of Travel to Thailand}

From time to time, these entrepreneurs flew to Thailand, stayed there for a while as they purchased their goods for sale, then flew to Congo, where they sold the products. All the entrepreneurs ran small scale business enterprises in Congo. Frequency of travel in international trade implies that the business is running well and that there are incentives to buy and sell, as well as explore changes or new opportunities in the market at a relatively higher rate. $60 \%$ (18) of the respondents traveled to Thailand at least once a month, $30 \%$ (9) traveled to Thailand at least once every three months, while 10\% (3) of the respondents travelled to Thailand at least once in 6 months. This shows that majority of the respondents travelled to Thailand more frequently and had either access to new business opportunities, had good business running or both.

\subsection{Sources of Capital}

Determining sources of capital is important for entrepreneurship, because it can help one to know whether a business is stable, growing, or likely to grow. 50\% (15) of the respondents said their capital was derived from, 
profit from prior business, $16 \%$ (5) respondents reported that their sources of capital was from current profit, 23\% (7) said their income was from family and friends support, while $11 \%$ (3) had their capital from microfinance institutions. This results show that majority of the respondents had their income from prior business. This implies that considering similar circumstances, women who had prior stable business were likely to gain capital to venture into international trade as entrepreneurs. In this case, their prior business stability and income provides a stable capital base to advance into new business ventures. The number of women who reported their current businesses as the sources of capital was far much below compared to those who gained capital from their prior businesses as well as those who gained support from their families. These results also indicate that support from family and friends remain important source of capital for female entrepreneurs. This also means that the female entrepreneurs' family socio-economic status or willingness to support the entrepreneur is a factor in determining whether female entrepreneurs will enter participates in international trade or not.

\subsection{Professional Training in Business}

Professional training is important for business because it equips entrepreneurs with skills, knowledge and competence necessary for managing their businesses. The results of the study show that $83 \%$ (25) of the respondents had no professional training in business, but relied heavily on their practical experience as entrepreneurs. Of these $78 \%$ came from business families and had spent larger part of their lives in business. On the other hand $17 \%$ (5) of their respondents Bachelor degrees in business, marketing or economics. This shows that majority of the respondents based their international trade competencies on their experience. The study also shows that apart from education the family unit remains a major socio-economic institution that plays an important role to prepare women for international entrepreneurship.

\subsection{Reasons for Choosing International Trade/Entrepreneurship}

Regarding the question: Why did you choose your particular business venture? 50\% (16) of the respondents cited influence from family, 26\% (8) of the respondents cited lived experiences within which they discovered business opportunities for example, scarcity of particular goods and services, while $21 \%$ (7) of the respondents chose these business because of access to information either through a network of friends or through education. Some women entrepreneurs had chosen their businesses because of the business opportunity that they discovered through their own lived experiences. One such participant chose to do jewelry business because she missed the types of jewelry that fit her needs on the market. As a result she decided to meet these needs for customers like her. Besides she loved the jewelry business too. "My entrepreneurial venture falls in the jewelry industry and I run a company that makes and sells different types of jewelry and accessories items such as anklet, bracelet, earrings, nose ring, and waist chains. I chose this particular venture because I myself love accessories and sometimes, cannot find the perfect match for my outfits." She said. Other entrepreneurs chose their business because it was something they wanted to do since they were young and they had nurtured this dream as they grew up. One participant said "I chose this business because it was my childhood dream, and I've always dreamt to be my own boss. So I decided to study management so that I could manage my own business and now I am doing it."

\subsection{Lack of Capital}

Lack of capital was cited as a challenge to respondents businesses with $86 \%$ (26) of the respondents citing it as a problem to their business compared to $14 \%$ (4) who did not. Those who did not cite lack of capital as a challenge to their business reported that they had established business that ran largely on orders. This means that they received enough money before they delivered the goods to their customers. This means that that business strategy and business establishment reduced constraints on the respondents' need for capital before they run business. Other cited family contribution as adequate contribution to their capital as one participant suggest below.

Fortunately for me, I have not had a lack of capital because I have had the full support of my family behind me. Before I even started my venture, I made sure my funds would come through and it would be enough for me to start my operations. My capital came from parents' funds and that's what I initially started on. For women entrepreneurs who wish to obtain funds as means of capital, in my opinion, should not be facing discrimination 
on getting those loans just because they are women.

\subsection{Lack of Information}

"You need to be well informed on your line of business in order for you to be successful. Entering a business that you are not well informed on usually leads to failure of the business" said a participant. The results of this study show that $76 \%$ (23) of the respondents reported that lack of information affected their business while $24 \%$ (7) of the respondents did not. Access to information can also be as a result of the abilities of the entrepreneur to make sense of information within the business environment as one participant suggests below:

There's lots of information all around us out there; we just have to go and grab it. If an entrepreneur wants to know something and do prior research, there is nothing that stops that individual. I do not believe in lack of information since we live in a very tech-savvy world these days, where almost anything can be found on the internet. However, some challenges that may arise in obtaining information is that it may be identical and nothing new to receive. What you find may have already been found by other competitors, and therefore information doesn't remain new or unique. Another challenge that women entrepreneurs may face that leads to lack of information is a weakness of connections. If the entrepreneur isn't a social being, then that can be a setback because information always doesn't come knocking on your door; people have to go out and find it.

Respondents who did not report lack of information as a problem to their business indicated they had either a social network that provided them with access to information, or had access to information technologies from which they sought the information they needed. This implies that social networks and modern information technologies provide a platform for entrepreneurs to access the information they need for business as one participant suggests below:

I think I got all the information required for my business. Firstly thanks to the internet that provides all the information needed for the success of the business. Also I have many friends worldwide who help me with necessary information about the different areas where they.

\subsection{Lack of Skills}

Results from this study shows that $43 \%$ (13) of the respondents reported lack of skills as a hindrance to their business while $57 \%$ (17) of the respondents did not consider it a hindrance. This implies that majority of the respondents had confidence in or considered their skills adequate for their businesses. Some of those who did not consider lack of skills a threat to their business considered using business networks to provide for the skills they needed, which they did not have as entities. In this case, lack of skills is considered a business expense rather than a threat to business, as one of the respondent suggests “...because I believe in business/entrepreneurship you can never lack skill and whatever one lacks you can always find or pay some to do what one lacks. And it’s about risk taking because you can never $100 \%$ assurance."

Lack of skills was also considered a less or no threat when one is experienced in entrepreneurship. It is assumed that some of the business needs which require skills are addressed with the experience an entrepreneur acquires over time as one respondent suggests "Presently I'm well skilled for my business because I've been in this business for 10 years today guess the you're are used in doing something, the expert u become in doing that particular thing."

Another view to lack of skills is that lack of skills is not general, rather relative to women entrepreneurs. This means that it depends with the women entrepreneurs themselves and the circumstances under which women entrepreneurs do their business. In light of this, one respondent suggests:

Certain women entrepreneurs definitely lack essential skills of carrying the responsibilities and becoming a good entrepreneur who indulges in risk taking and knows how to sell. This doesn't mean however that all women lack skills in being an entrepreneur. There are some that are better than others, and some who have a lot of room for improvement. Entrepreneurial skills can be honed and sharpened, but only with practice of being in business. I believe a successful entrepreneur is one who has faced and learned from failures, and not just one who has been dependent on success.

\subsection{Lack of Business Partners}

Results of this study show that $83 \%$ (25) of the respondents reported lack of business partners as a challenge to 
their businesses compared to $17 \%$ (5) respondents who did not experience this challenge. Those who did not express the lack of business partners as a threat to their businesses were sole entrepreneurs who had developed a strong tradition of sole entrepreneurship and therefore considered it a factor in their business success. One participant suggested "You don't always need business partners to succeed in a business. Some businesses are better off done as individuals. Other considered trust as a major which, in which case trust would be a problem in case of business partnership than it would in sole proprietorship. One participant for instance suggested “...because trust plays a major role in the growth of the business and you want to find someone who can share support because two brains are better than one."

Another view in preference to sole proprietorship over business partnership is based on the personal experience of the entrepreneur, particularly when the entrepreneur considers self, based on business experience as being better off without business partnership. Such differences may entail personal beliefs, views, and goal differences. One participant for instance suggests that: I do not feel that personally in my venture, I lack any partners because I know I do not work too well with extremely large groups. Because I am a perfectionist, I tend to do things on my own, due of my high expectations from people.”

\subsection{Cultural Beliefs Hinder Business}

This study reports that 93\% (28) of the respondents reported that cultural beliefs hinder business while 7\% (2) reported that cultural beliefs did not affect their business. Respondents who reported cultural beliefs as having hindrance on businesses identified factors such as trust: cultural sensitivity, client customer behaviors, and behavior conflict between the entrepreneur and the market. Regarding this, one respondent for instance suggests the following: “... Understanding the importance of culture and respecting the role it plays in the lives of potential customers in foreign markets is vital and could mean the difference between the success and failure of your overseas ventures. If you belief is completely opposite from your new market's belief, you might not be making as much as you would in another country or environment where you both share the same beliefs.”

\subsection{Government Laws/Regulations Hinder Business}

The findings of this study show that $96 \%$ (29) of the respondents reported that government regulations hinder business while $4 \%$ (1) of respondents did not consider government regulations a hindrance. Some of those who reported government regulations as a hindrance to business cited corruption, tax burden on entrepreneurs, and politics as some of the reasons why government regulations on businesses don't work. One participant for instance suggests: "I believe they do because there are very few countries in this world that do not engage in corruption. Because of corruption, politics, and harsh rules and regulations that businesses need to comply with at all costs; an entrepreneurship cannot always go as planned."

\subsection{Politics Hinder Business}

Results of this study show that $50 \%$ of the respondents reported that politics hinder business while $50 \%$ did not consider it a hindrance. The most common political issues raised were about political influence on taxes, minimum wage, and national security. One respondent for instance suggests the following: "Politics can affect businesses both negatively and positively through changes made to tax, labor and national security laws. For example, politicians can raise taxes directly on businesses or on individuals, which ends up costing companies in the long run as people spend less money on goods and services."

The other view to political influence on business is the government inaction over illegal business, which undermines legitimate businesses performance and opportunities to make profit. Regarding this, one participant suggests "Because of too much underground business, it is hard for businesses to find proper capital and make profit due to the poverty caused by politics." Another related view suggests that political stability affects business, for instance one participant observed "Unsustainable governments, corruption and political subjections can very much hinder a business because you never be ready for politics throw at you, which would also hinder the financial market.”

\subsection{It Is Harder to Obtain Capital Based on Gender}

The results of this study shows that 73\% (22) of the respondents reported that it is harder to obtain capital based 
on gender while $27 \%$ (8) of the respondents did not consider it as an issue. Some of those who did not report access to capital as a problem had been in business for long or had support from family networks. Regarding this, one participant suggests the following: "No, I do not feel it is harder as I think about my case when I first started my business in this line. Capital, as mentioned earlier, was provided by the funds of family support (mostly parents) and they were motivating me to continue with my business because my father is also an entrepreneur. The same way a man raises capital for business, a woman can obtain those same methods to get for her entrepreneurial venture.”

\subsection{Women Face Discrimination in Business}

The findings of this study indicate that $66 \%$ (20) of the respondents reported that women face discrimination in business while $34 \%$ (10) of the respondents did not. Some of the respondents who reported discrimination attributed it to cultural views and norms for instance one participant suggests:

Females are always viewed as pushovers as well as unfit to mingle and play with the big dogs. Our seriousness and entrepreneurial abilities are always under estimated. So yes it is very difficult to gain trust when asking for any sort of investment capital and we have to work twice as hard.

Another view to the discrimination of women in business is that there appears to be a world view in which business roles are stereotyped and socially allocated to women and men. By doing so, society expects women to choose to do business to fit in these categories rather than creatively do something of their choice. Regarding this, one participant suggests: "Women definitely face discrimination in business, whether it's in operating their own business or during a hiring process for an employer... For example, people hold a stereotype for women and they feel that women are not suitable for Sales jobs as it demands traveling to unknown places, speaking to unknown people, working late nights and so on.”

\subsection{Men Are Respected More in Business than Women}

The findings of this study shows that $60 \%$ (18) of the respondents reported that men are more respected in business than women compared to $40 \%$ (12) who reported it not an issue. Some of who reported that men are respected more than women indicated attitudinal reasons for instance one participant suggests "Because men are looked at as the pioneers of business and women could work at the same position or even higher than males but get paid less. Men are seen as stronger and very decisive counterparts than women hence being of more importance."

Another view to this is that respect for men or women in business depends on the type of business the entrepreneurs are doing. One participant for instance suggests "it depends with what kind of business you are involved in for you to be respected. If you are in to the fashion business and sell clothes or anything you will be treated differently from someone selling electronics regardless of your gender.”

A contrary view to this is that which focuses on the changing times, where a participant suggests that even though culture has contributed to the differences in the way men and women are respected in business; time are changing and so respect for women compared to men is relative and subject to the changing times.

It depends on the culture people are doing business in. While some may think that women get respected less in places like the Middle East or even some Muslim or strict Hindu nations, some of these can actually be considered myths. I personally believe that we are moving towards a business world where women are equally respected, if not more, than men. The business world is a very diverse one and it obviously depends on what industry as well. All in all, however, I would say that men do not get more respect or are taken more seriously just because of their gender. I do believe that double standards still exist, but in a bigger picture, women also are well respected when conducting business or having one on their own. Back in those days women were under estimated so now when people see a woman that has achieve her goals they are astonished and amazed which thereby make them to respect her more.

\section{Discussion}

The results of the study show that: government laws and regulations; cultural beliefs; lack of capital; lack of business partners; lack of information; difficulties to obtain capital based on gender; discrimination against women in business; and availability of more women in business than women highly affected women entrepreneurs in Congo. Politics had an average effect while lack of skills had much less effect below average. Contrary 
to the hypothesis of this study, the results indicate that female entrepreneurs under this study were not equipped to face and tackle external challenges that affected their organizations. Consequently external threats to young female entrepreneurial ventures outweighed their capacity to address them.

The findings of this study also indicate that young female entrepreneurs draw from their own experience, social networks, and family support resources that they use to address challenges their organizations face. Most of the female entrepreneurs under this study indicated strong family support. Some had experience going way back to their childhood since they grew up participating in family business and gaining hands on experience, knowledge and skills on how to do business. Others benefited from social networks that enabled them to travel, and access information which they used to build organizational resilience against environmental threats.

Earlier studies have shown that professional training is important for business because it empowers entrepreneurs with skills, knowledge and competence necessary for managing their businesses. In light of this view, the results of the study show that $83 \%$ (25) of the respondents had no professional training in business, but relied heavily on their practical experience as entrepreneurs. Of these $78 \%$ came from business families and had spent larger part of their lives in business. On the other hand, $17 \%$ (5) of their respondents Bachelor degrees are in business, marketing or economics. This shows that majority of the respondents based their international trade competencies on their experience.

However, most these entrepreneurs under study had acquired their skills and competencies from hands on experience, while participating in family business as they grew up. This has several implications. The first implication is that this study shows that family business plays a role in international entrepreneurship as an informal practical training school. The second implication is that in the absence of or when business people especially women do not have access to formal trainings for different reasons; family business play that function. It may be the most accessible if not the only choice for disadvantaged groups in business. The third implication is that experience played a major rule in informing the skills and competencies of the participants under study than professional training. In this case, further research for instance larger surveys should be done to show for instance the extent to which female entrepreneurs rely on informal training and experience compared to professional training in Congo.

The way men speak in business may earn them respect, and while women speak like men do, they are alienated. Men for instance: swear more at work place hence sound convincing; they speak louder than women; interrupt more; generally speak out more in business meetings; and use declarative statements. This makes them effective in boosting morale and confidence. This implied that respect in business is perceived, acquired and given along gender lines. In light of this, the findings of this study shows that $60 \%$ (18) of the respondents reported that men are more respected in business than women compared to $40 \%$ (12) who reported it not an issue. However, another view to this is that respect for men or women in business depends on the type of business the entrepreneurs are doing. If this view is to by, it suggests that the problem is not the immediate business situation where women are less respected than men; but rather, societies has already gendered types of businesses and classified which ones are for women and which ones are for men. Therefore, when a woman is found doing business perceived to be a man's business, she is less respected.

Earlier studies have shown that in many countries, cooperatives provide a strong resource for women to advance their business successfully. However, few women reach decision making levels in the management of cooperatives. This means that women issues do not feature much in decision making. There is also lack of gender agenda in business negotiations and bargaining. Most business laws and regulations give advantage to men than to women with World Bank survey of 143 countries indicating that $90 \%$ of these countries have atheist one policy that differentiates. In Democratic Republic of Congo and Pakistan for instance, women are restricted from opening bank accounts [23]. In light of this view, the findings of this study indicate that $66 \%$ (20) of the respondents reported that women face discrimination in business while $34 \%(10)$ of the respondents did not.

Another view to the discrimination of women in business is that there appears to be a world view in which business roles are stereotyped and socially allocated to women and men. By doing so, society expects women to choose to do business to fit in these categories rather than creatively do something of their choice. Such situation is possible for example if the woman is from a particular religion, color, or race that falls in the minority of that industry [24].

While some of the findings of this study for example discrimination, and socio-cultural practices that limit women's opportunities in entrepreneurship can be found in the experiences of women entrepreneurs in other parts of the world; this study shows that the family unit plays a more central role in providing business oppor- 
tunities for young female entrepreneurs in Congo, especially in the absence of government intervention; and when such young female entrepreneurs lack access to professional training and private sector incentives. Therefore, while in other studies, economic institutions such as financial institutions or political institutions such as government assume a prominent role in the discussion of empowering young female entrepreneurs; this study uniquely shows that one thing often goes unnoticed-that is family. Therefore, policies or private sector interventions that will provide a more effective solution to challenges young female entrepreneurs face must add to its agenda and priorities, the family unit.

\subsection{Recommendations}

Practitioners in entrepreneurship should focus on:

1) Promoting skills and knowledge sharing to enhance experience, knowledge, creativity and innovation.

2) How to maximize profits and to venture into new sources of capital.

3) Customized programs for professional training and development of female entrepreneurs.

4) Providing incentives for instance access to information and reforms in trade policies for example increasing infrastructure such as internet access and, promoting family based economic policies.

\subsection{Limitations of the Study and Directions for Future Research}

Because of resource and time constrains, this study takes a case study approach intended to provide an understanding of the challenges young female entrepreneurs face and the resources they need. Since this is a single case study, the findings of the study cannot be generalized as the basis for the entire view of challenges young female entrepreneurs face. During data collection, getting more participants was a challenge. This is partly because there are no government records from which one can know how many such entrepreneurs are in Congo. Such records would provide an opportunity to identify and reach out to more participants. The other major challenge was language barrier. Most of the participants were fluent French speakers while the thesis was conducted in English. As a result, the researcher translated the questionnaires and into French and conducted focused group discussion in French before translating the data into English and then analyzing. Some concepts are lost or tend to lose weight through translations besides the time constrains spent on translation process.

\section{References}

[1] Gough, J.W. (1969) The Rise of the Entrepreneur. Schocken Books, New York.

[2] World Bank (2010) Entrepreneurship Snapshots 2010: Measuring the Impact of Financial Crisis on New Business Registration. http://econ.worldbank.org/research/entrepreneurship

[3] Naudé, W.A. and Havenga, J.J.D. (2005) An Overview of African Entrepreneurship and Small Business Research. Journal of Small Business \&Entrepreneurship, 18, 101-120. http://dx.doi.org/10.1080/08276331.2005.10593334

[4] Ngoyi, K.Z.B., Chand, M., Disashi, T.G., Lumbala, C.M. and Mbiye, B. (2012) Health Care Entrepreneurship in the Democratic Republic of the Congo: An Exploratory Study. Journal of African Business, 13, 87-100. http://dx.doi.org/10.1080/15228916.2012.693433

[5] Chirwa, E.W. (2008) Effects of Gender on the Performance of Micro and Small Enterprises in Malawi. Development Southern Africa, 25, 347-362. http://dx.doi.org/10.1080/03768350802212139

[6] Roberts, N.C. (2010) Entrepreneurship in Peace Operations. Journal of Civil Society, 6, 1-21. http://dx.doi.org/10.1080/17448689.2010.481908

[7] Su, D. (2009) Review of Ecology-Based Strategy Change Theories. International Journal of Business and Management, 4, 69-72. http://dx.doi.org/10.5539/ijbm.v4n11p69

[8] Munger, J.L. (2003) Retail Changes and Their Business-Business Markets. Journal of Business-to-Business Marketing, 10, 79-100. http://dx.doi.org/10.1300/J033v10n02_05

[9] McMenamin, I. (2008) Business, Politics and Money in Australia: Testing Economic, Political and Ideological Explanations. Australian Journal of Political Science, 43, 377-393. http://dx.doi.org/10.1080/10361140802267035

[10] Schneider, B.R. (2009) A Comparative Political Economy of Diversified Business Groups, or How States Organize Big Business. Review of International Political Economy, 16, 178-201. http://dx.doi.org/10.1080/09692290802453713

[11] Li, S.F. and Persons, O.S. (2011) Cultural Effects on Business Students’ Ethical Decisions: A Chinese versus American Comparison. Journal of Education for Business, 86, 10-16. http://dx.doi.org/10.1080/08832321003663330 
[12] Lee, S.H., Han, D.B. and Nayga Jr., R.M. (2014) Cultural Inflow Effects on Japanese Import Demand for Consumer Products: Importance of Halo Effects. Journal of the Asia Pacific Economy, 19, 506-521. http://dx.doi.org/10.1080/13547860.2014.908534

[13] Ahern, T.C. and Repman, J. (2014) The Effects of Technology Online. Journal of Computing in Education, 26, 537546.

[14] Deng, X. and Zhang, J. (2014) Differentiating the Effects of Internet Usage and Wireless Usage on Business-to-Business and Business-to-Consumer Ecommerce. Journal of Internet Commerce, 13, 138-157. http://dx.doi.org/10.1080/15332861.2014.934648

[15] Piérard, E. and Grootendorst, P. (2014) Do Downturns Cause Desperation? The Effects of Economic Conditions on Suicide Rates in Canada. Applied Economics, 46, 1081-1092. http://dx.doi.org/10.1080/00036846.2013.866204

[16] Kim, M. and Lee, S.Y. (2011) The Effects of Government Financial Support on Business Innovation in South Korea. Asian Journal of Technology Innovation, 19, 67-83. http://dx.doi.org/10.1080/19761597.2011.578426

[17] Moreno, J.D.J., Castillo, L.L. and Masere, E.D.Z. (2007) Influence of Entrepreneur Type, Region and Sector Effects on Business Self-Confidence: Empirical Evidence from Argentine Firms. Entrepreneurship \& Regional Development, 19, 25-48. http://dx.doi.org/10.1080/08985620601043372

[18] Rossman, G.B. and Rallis, S.F. (2012) Learning in the Field: An Introduction to Qualitative Research. 3rd Edition, Sage, Los Angeles.

[19] Fetterman, D.M. (2010) Ethnography: Step-by Step Guide. 3rd Edition, Sage, Los Angeles.

[20] Bernard, H.R. and Ryan, G.W. (2010) Analyzing Qualitative Data: Systematic Approaches. Sage, Los Angeles.

[21] Verhoeven, N. (2011) Doing Research: How and Why of Applied Research. LYCEUM, Chicago.

[22] Murchison, J.M. (2010) Ethnography Essentials: Designing, Conducting, and Presenting your Research. John Wiley \& Sons, San Francisco.

[23] Guiliano, M. (2009) Women, Work, and the Art of Savoir Faire: Business Sense \& Sensibility. Simon and Schuster, New York.

[24] Marston, A. (2014) Women, Business and Human Rights: A Background Paper for the UN Working Group on Discrimination against Women in Law and Practice. http://www.ohchr.org/ 